Como citar: Dutra, M. P. S., Pereira, L. G. S., Lemes, L. M. S., \& Faria, M. R. G. V. de. (2021). Hierarquia de valores: organização atual dos valores humanos em jovens universitários. PSI UNISC, 5(1), 68-81. doi:

10.17058/psiunisc.v5i1.15628

\title{
Hierarquia de valores: organização atual dos valores humanos em jovens universitários
}

\author{
Jerarquía de valores: organización actual de los valores humanos en los jóvenes \\ universitarios
}

\section{Hierarchy of value: current organization of human value in young university students}

Mickaele Pabline Siqueira Dutra

Centro Universitário de Anápolis (UniEVANGÉLICA), Anápolis - GO/Brasil

ORCID: 0000-0001-6215-3916

E-mail: mickaeledutra@outlook.com

Luanna Gomes Silva Pereira

Centro Universitário de Anápolis (UniEVANGÉLICA), Anápolis - GO /Brasil ORCID: 0000-0001-8888-1882

E-mail: luannagsp@hotmail.com

Lila Maria Spadoni Lemes

Centro Universitário de Anápolis (UniEVANGÉLICA), Anápolis - GO /Brasil ORCID: 0000-0001-5840-2799

E-mail: lilaspadoni@gmail.com

\section{Margareth Regina Gomes Veríssimo de Faria} Centro Universitário de Anápolis (UniEVANGÉLICA), Anápolis - GO /Brasil ORCID: 0000-0001-5825-2364

E-mail: margarethverissimo@gmail.com

\begin{abstract}
Resumo
O estudo tem como objetivo investigar quais os valores predominam e como estes são hierarquizados entre os jovens universitários; analisar como esses valores influenciam nos comportamentos cotidianos desses jovens e como determinam as práticas de ensino-aprendizagem e o relacionamento entre docentes e discentes para a formação desses valores. Tem sua metodologia de execução estruturada em uma abordagem à pesquisa quantitativa, qualitativa e descritiva, que analisa os resultados por meio de correlação da realidade empírica com a teoria que embasa o estudo. Para isso, realizou-se uma pesquisa de campo com 140 estudantes universitários, através da aplicação de um questionário embasado principalmente na teoria de Valores Humanos de Schwartz (1992). Os resultados demonstraram que há um conflito dentre os valores hierarquizados como mais importantes pelos universitários. Por um lado, estão a benevolência e o universalismo, que são valores autotranscedentes, e por outro lado, o hedonismo, que é um valor intrínseco, voltado para à abertura à mudança. Outro ponto a ser destacado é que os universitários consideram que esse ensino de valores deve ser feito preponderantemente pela família. Contudo, quando evocados sobre valores ensinados pelos seus professores, mencionam valores conservadores. Conclui-se que existe um choque de valores entre os que são ensinados pela família e os que são ensinados pelos professores, o que pode ser percebido através da hierarquização de valores.
\end{abstract}

Palavras-chaves: Valores; Universitários; Hierarquia; Schwartz; Professores.

\section{Resumen}

El estudio tiene como objetivo investigar qué valores predominan y cómo estos están jerarquizados entre los jóvenes universitarios; analizar cómo estos valores influyen en los comportamientos diarios de estos jóvenes y cómo determinan las prácticas de enseñanzaaprendizaje y la relación entre profesores y estudiantes para la formación de estos valores. Su metodología se estructura en un enfoque de investigación cuantitativa, cualitativa y descriptiva, que analiza los resultados 
mediante la correlación de la realidad empírica con la teoría que subyace al estudio. Con este fin, se realizó una investigación de campo con 140 estudiantes universitarios mediante la aplicación de un cuestionario basado principalmente en la teoría de los valores humanos de Schwartz (1992). Los resultados mostraron que existe un conflicto entre los valores jerarquizados como más importantes por los universitarios. Por un lado, está la benevolencia y el universalismo, que son valores auto-trascendentes, y por otro lado, el hedonismo, que es un valor intrínseco, orientado a la apertura al cambio. Otro punto a destacar es que los estudiantes universitarios consideran que esta enseñanza de valores debe hacerse predominantemente en la familia. Sin embargo, cuando se evocan los valores enseñados por sus maestros, mencionan los valores conservadores. Se concluye que existe un choque de valores entre los enseñados por la familia y los enseñados por los profesores, que se puede percibir a través de la jerarquía de valores.

Palabras clave: Values; Estudiantes universitarios; Jerarquía; Schwartz; Profesores.

\footnotetext{
Abstract

This study has as a goal to investigate what values dominate and how they are ranked between the college
}

students; analyze how these values influence the daily behavior of these people and how they determinate the teaching-learning practices and the relationship of formation of values between teachers and students. It also has its execution methodology structured by a quantitative, qualitative and descriptive research approach, they analyze the results through empiric reality correlation with a theory that supports the study. A field research was realized with one hundred and forty college students, through an application of a quiz based on Human Values Theory by Schwartz (1992). The results demonstrate that there is a conflict on ranked values as more important by these students. On the one hand, there is benevolence and the student, they are selftranscending values, by the other hand the hedonism, it is an intrinsic value, facing the changing and opening. Another point to be detached is that students consider this values teaching must be done predominantly by the family. Nevertheless, when evoked about values taught by their teachers, they mention conservative values. Conclude that there is a value choc between those who are taught by family and those who are taught by teachers, it may be noticed trough the values rank.

Keywords: Values; College students; Hierarchy; Schwartz; Teacher.

\section{Introdução}

Os valores estão presentes na humanidade desde os povos primitivos, para auxiliar, guiar e garantir a sobrevivência. Cunningham e Reiche (2002), ao pesquisar sobre as civilizações antigas, como a do Egito, China e Roma avaliam que a presença de valores foram fundamentais para a preservação da vida que se encontrava em constante ameaça. Talvez por isso, o estudo dos valores tem sido abordado por diversas disciplinas do conhecimento, e sendo fundamentada por variadas perspectivas, psicológicas, antropológicas e sociológicas, contemplando variações culturais, históricas e conceituais.

O principal modelo da psicologia nos dias atuais, que serve de referência ao embasamento teórico dos campos de pesquisa sobre valores humanos, foi desenvolvido por Rokeach (1973), e, posteriormente sedimentado por Schwartz (1992). Sendo assim, as possíveis semelhanças entre as duas teorias não são eventuais, como reconhece Schwartz, que adota o conceito de valores empregado por Rokeach, elaborando assim, uma tipologia de valores universais, detalhando as suas estruturas relacionais e dinâmicas (Lima, 2012). Para ambos, os valores são recursos utilizados pelas pessoas como critério para selecionar, justificar e julgar acontecimentos, de si e dos outros, sendo estruturas duráveis, que, no entanto, podem sofrer alterações ao longo da história.

De acordo com Gouveia (2013) esses tipos motivacionais são resultados de três necessidades humanas universais: 1- as necessidades básicas, ligadas ao organismo em si; 2- os motivos sociais, ligados à interação desse organismo com o ambiente; 3- e as demandas institucionais, que são ligadas a satisfação do organismo inserido em seus grupos. À partir disto, Schwartz (2003) classifica os valores humanos em dez tipos motivacionais, divididos em quatro orientações fundamentais, que por sua vez são organizadas por meio de duas dicotomias, sendo a primeira a oposição entre autotranscedência (benevolência e universalismo) 
autopromoção (realização e poder); e a segunda a oposição entre abertura à mudança (hedonismo e estimulação) vs. valores de conservação (segurança, tradição e conformidade), como podem ser visualizados na Figura 1.

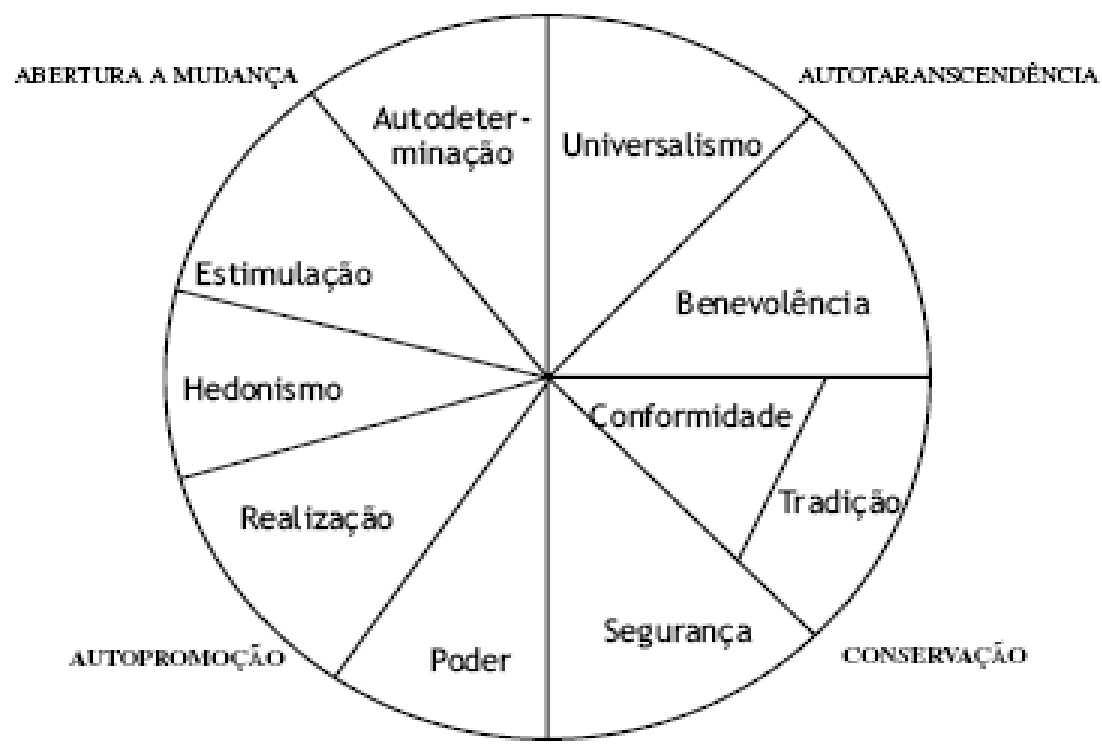

Figura 1. Estrutura Circular dos Valores segundo Schwartz(1992).

Nas dimensões autopromoção e autotranscendência, os valores de realização e poder se opõem ao universalismo e benevolência. Os valores de autopromoção refletem uma busca pelos próprios interesses, enquanto que os valores de autotranscedência envolvem preocupação com o outro.

Nas dimensões de abertura a mudança e conservação, os valores de estimulação e autodireção se opõem a tradição, segurança e conformidade, sendo que os primeiros prezam pela independência de pensamentos, sentimentos e prontidão para novas experiências, e os segundos, resistência a mudança, auto restrição e ordem. Desta forma, ao hierarquizar valores, indivíduos e culturas pendem para um dos lados destas dicotomias, valorizando mais às mudanças ao invés das tradições, ou valorizando mais à autotranscedência ao invés da autopromoção e vice-versa em ambos os casos.

Ross e Schwartz (1995) dividem os valores em nível individual e nível cultural. Os valores que se encontram em nível individual representam os objetivos motivacionais das pessoas e serve como princípio orientador em suas vidas, produto de uma cultura compartilhada e resultado de uma experiência única de cada ser. Já os valores no nível cultural possuem a representação de ideias abstratas, compartilhadas na sociedade, sobre o que é certo, bom e desejável. Estes últimos servem como estrutura para as normas que são compartilhadas e guiam o comportamento apropriado em cada situação. Desta forma, cada tipo de valor é definido por diferentes interesses, que podem ser individualistas (poder, realização, hedonismo, estimulação e autodireção), coletivistas (tradição, conformidade e benevolência) ou mistos (segurança e universalismo).

A partir desse modelo, Schwartz (2003) trabalhou o conceito de cada tipo motivacional, assim como suas orientações e funções, adequando-os em formato de itens de questionário, criando uma escala na qual as afirmações são expressas com clareza para pessoas em diferentes níveis de instrução.

A Tabela 1, clarificará quais as orientações de cada tipo motivacional, suas funções e quais os itens representados no instrumento dos valores humanos de Schwartz 
Tabela 1

Tipos motivacionais de Schwartz.

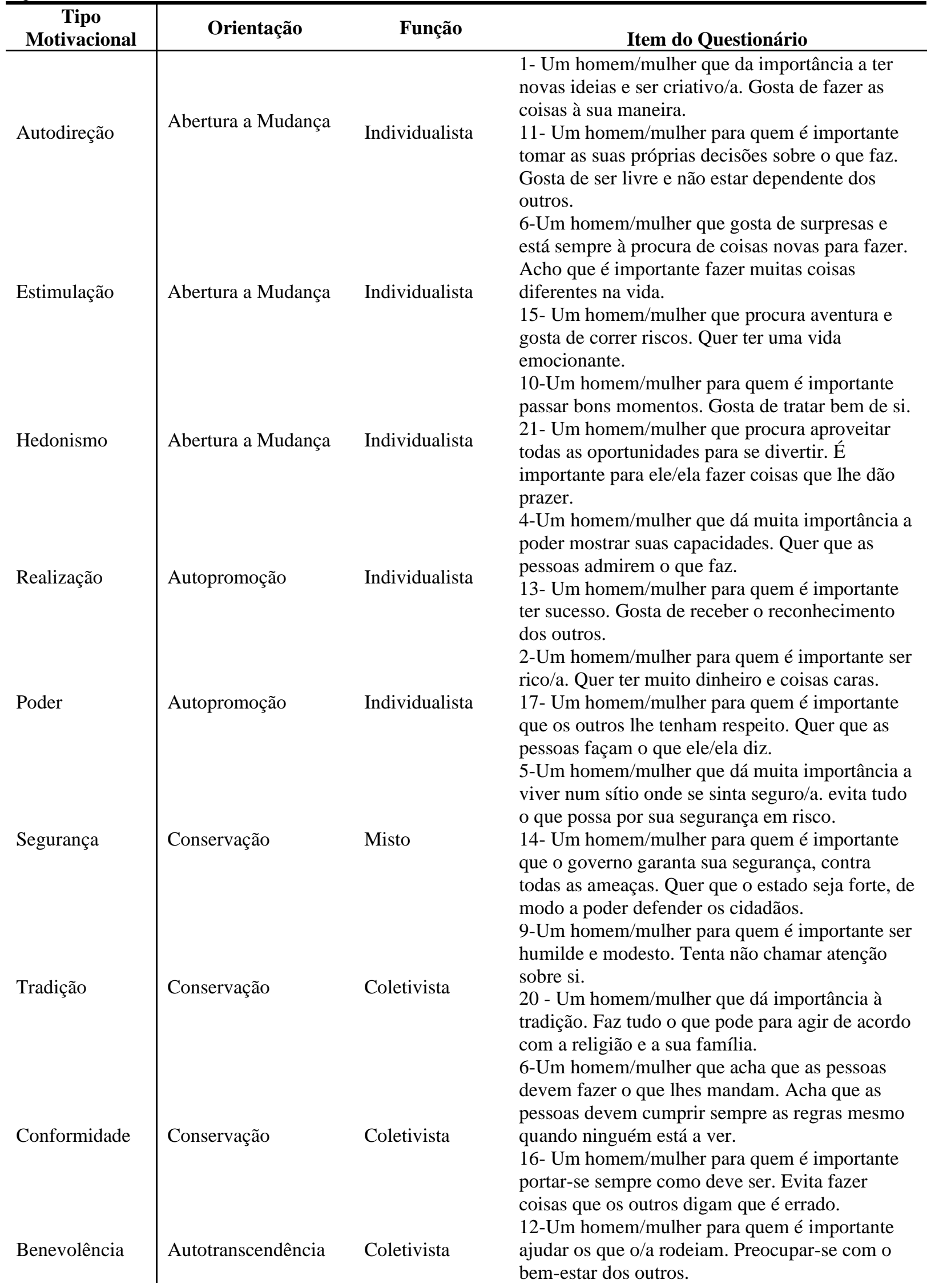




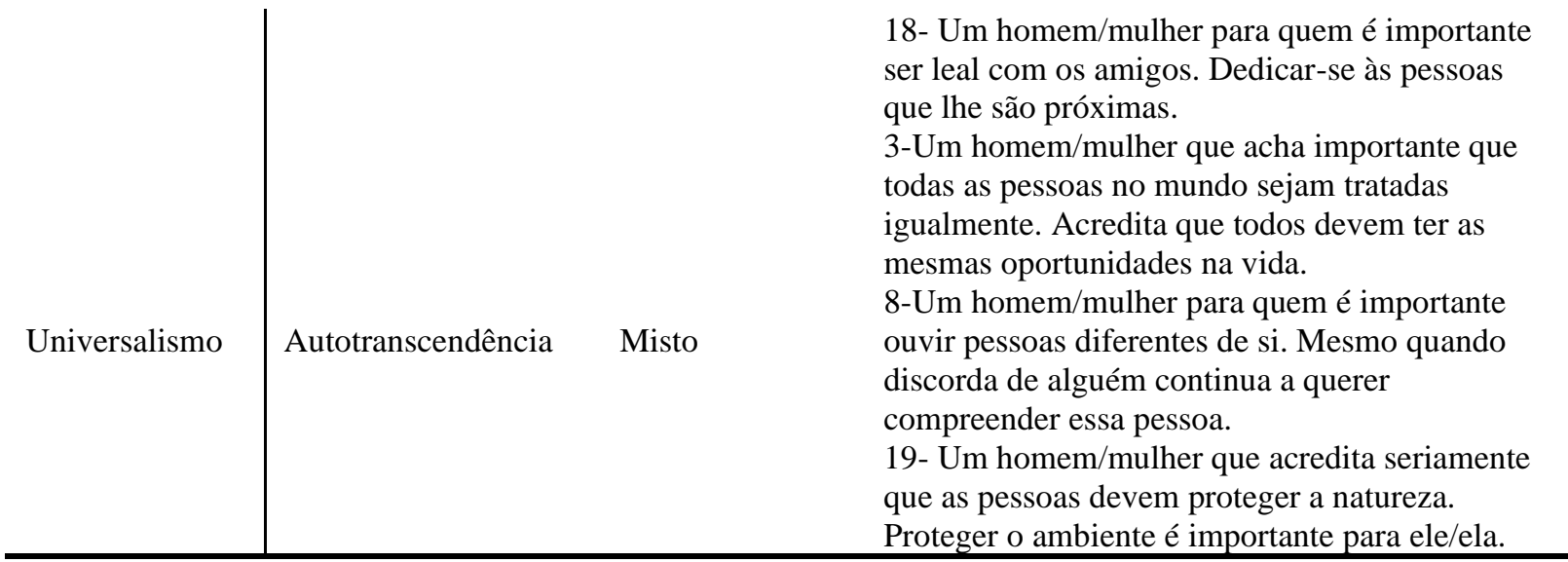

Rokeach (1979) afirmou que os valores servem para assegurar a coerência das ações e pensamentos, pois quando o indivíduo se depara com uma situação conflitante, ele avalia quais atitudes a serem tomadas, mediante a hierarquia de valores que entendem como mais importantes. Desta forma, os valores são sempre comparados e hierarquizados. Sobre isso, há um estudo recente sobre universitários brasileiros de duas instituições de ensino superior, uma estatal e outra não-estatal, com o objetivo de analisar a hierarquia dos valores correlacionando-os com as informações obtidas nos dados sociodemográficos (Menezes, Costa \& Campos, 1989). Os resultados demonstram que a hierarquia de valores para esses jovens prioriza a maturidade social e relacional, para depois valorizar o hedonismo, o sucesso conformista e a manutenção da tradição. A análise das diferenças revela que as mulheres dão mais importância aos valores da maturidade enquanto que indivíduos que se declararam nada religiosos, possuem resultados de hedonismo significativamente mais elevados.

Nesse sentido, estudos sobre a hierarquia de valores das novas gerações podem sinalizar mudanças na sociedade, pois de acordo com La Taille (2009) os valores determinam a moral que consequentemente embasam os comportamentos. Ainda segundo o autor, estamos vivendo uma cultura da vaidade baseada nas aparências alimentadas pelo consumismo sendo que essas mudanças na cultura são perceptíveis quando analisamos a hierarquia de valores.
Portanto, o presente estudo tem como objetivo investigar quais os valores predominam entre os jovens universitários e como estes hierarquizam seus valores. Pretende-se ainda analisar como esses valores influenciam as práticas de ensinoaprendizagem e o relacionamento entre professores e alunos no ensino de valores.

\section{Método Estratégia Metodológica}

Trata-se de um estudo de campo, transversal, com aplicação de questionário.

\section{Participantes}

Fez parte da amostra um total de 140 alunos de um centro universitário de caráter confessional do estado de Goiás, sendo aproximadamente $70 \%$ do sexo feminino, $25,7 \%$ do sexo masculino e $4,29 \%$ não responderam. A média da idade desses universitários foi de 22,3 (DP=6,4). Os participantes foram selecionados de forma aleatória e randomizada.

\section{Instrumentos}

Para a coleta de dados, foi utilizado um questionário, destinado aos alunos. Este continha uma questão de evocação (Flament \& Rouquette, 2003), utilizando como termo indutor a frase "Você se lembra de alguns valores morais que você aprendeu, que foram ensinados pelos professores em algumas disciplinas? Cite-os." 
Logo após da evocação, foi apresentada uma Escala Likert, a fim de verificar o quanto estes acadêmicos acreditavam que os professores estavam preparados para ensinar os valores evocados (em uma escala onde 1 significava pouco preparado e 4 significava muito preparado).

Uma questão de atribuição de responsabilidade, onde os participantes distribuíram numa escala de 8 pontos o quanto eles consideravam de responsabilidade da faculdade, do professor e da família o ensino moral dos alunos.

Posteriormente, duas questões de ordenação de importância (em uma escala onde 1 significava pouco importante e 4 significava muito importante) o quanto os participantes consideravam importante a relação entre aluno e professor no aprendizado dos valores mencionados e quanto eles consideravam importante o conteúdo ministrado nas disciplinas também para o aprendizado desses valores.

Finalizando o questionário, uma Escala de Valores Humanos de Schwartz (1992), traduzida e validada para o Brasil por Tamayo e Schwartz (Porto \& Tamayo, 2007), composta por 21 itens que refletem 10 valores motivacionais divididos em quatro orientações fundamentais: autotranscendência vs. autopromoção e abertura à mudança vs. valores de conservação.

Deste modo, o questionário é composto por 1 questão aberta e 5 questões fechadas, somadas ao Termo de Consentimento Livre e Esclarecido (TCLE) para autorização do uso dos dados coletados de forma independente e anônima, todos aplicados de forma coletiva e unificada.

\section{Procedimentos}

A amostra foi colhida dentro das dependências do Centro Universitário, aproveitando os inícios e finais das aulas, e, quando necessária, a autorização de algum professor para que a aplicação fosse realizada durante o horário de aula. $\mathrm{O}$ instrumento era aplicado aos acadêmicos dos cursos de Direito e Psicologia da Instituição, após um contato direto e formal das pesquisadoras, salientando quais os objetivos da coleta de dados e qual a importância dos participantes que estavam dispostos a participarem da pesquisa. Durante a coleta de dados, as pesquisadoras esclareciam possíveis dúvidas a respeito do preenchimento do instrumento e após este, eram recolhidos os instrumentos e os TCLE.

Todas as providências em relação à dimensão ética do estudo foram tomadas de acordo com a Resolução de ética 466/2012 do Conselho Nacional de Saúde. O estudo foi aprovado pelo Comitê de Ética em Pesquisa do Centro Universitário de Anápolis UniEvangélica, sob $\quad \mathrm{o} \quad \mathrm{n}^{\mathrm{o}}$ 75581717.5.0000.5076 do CAAE.

\section{Resultados e Discussão \\ 1. Hierarquia dos tipos motivacionais}

Para analisar a hierarquização dos valores através da escala de Schwartz (1992), utilizaremos da análise estatística de média e desvio padrão para verificar quais os tipos motivacionais que mais se destacaram. A Tabela 1 a seguir, apresenta as médias em ordem decrescente, estando o tipo motivacional que obteve maior média (Benevolência, $\mathrm{M}=$ 5,$2463 ; \mathrm{Dp}=0,86709$ ) no topo da Hierarquia e o tipo motivacional que obteve menor média (Poder, $\mathrm{M}=3,2630 ; \mathrm{D}=1,25459$ ), na base.

O tipo motivacional que se destacou e obteve maior média 5,2 (Dp=0,86) nas respostas dos acadêmicos foi à benevolência. A benevolência é definida como a busca do bem-estar das pessoas próximas, com quem se mantém relações de intimidade. Isto acontece porque a benevolência tem como fonte a interação do organismo com seu grupo, portanto, preserva-se o grupo com que se mantém proximidade e trocas afetivas (Gouveia, 2013, p. 86). Podemos considerar que essa seria uma caraterística das novas formas de configurações de família, que tornaram a família um ambiente privado no qual as pessoas refugiam-se contra as mazelas 
e ameaças do mundo externo. Além disso, podemos considerar a obra de Almeida (2015) que através de dados de um amplo survey, concluiu que o brasileiro é familista no sentido de privilegiar as pessoas que eles consideram da família. Desta forma, a prevalência deste valor da benevolência confirma essa tendencia de priorizar as pessoas que são próximas em detrimento do bem de todos.

O bem estar de todos é caracterizado nesse modelo como universalismo que obteve média $5(\mathrm{Dp}=0,83)$ ocupando segundo lugar na Tabela 2

Frequência, média e desvio padrões da hierarquia dos valores.

\begin{tabular}{c|c|c|c|c}
\hline & Número & Média & Desvio Padrão & Erro padrão da Média \\
\hline Benevolência & 136 & 5,2463 &, 86709 &, 07435 \\
Hedonismo & 134 & 5,0373 &, 81947 &, 07079 \\
Universalismo & 134 & 5,0572 &, 83424 &, 07207 \\
Autodireção & 136 & 4,8419 &, 94222 &, 10345 \\
Realização & 136 & 4,3125 & 1,20637 &, 09758 \\
Tradição & 134 & 4,1567 & 1,12960 &, 10146 \\
Estimulação & 136 & 4,1140 & 1,18316 &, 09353 \\
Segurança & 135 & 3,9556 & 1,08667 &, 10694 \\
Conformidade & 133 & 3,4135 & 1,23324 &, 10798 \\
Poder & 135 & 3,2630 & 1,25459 & \\
\hline
\end{tabular}

Por outro lado, os valores menos importantes para os participantes são poder $(\mathrm{M}=3,26, \mathrm{DP}=1,25)$, conformidade $(\mathrm{M}=3,41$, $\mathrm{DP}=1,23)$ e segurança $(\mathrm{M}=3,95, \mathrm{DP}=1,08)$, sendo todos eles valores predominantemente conservadores ao contrário do hedonismo que é um valor de abertura à mudança. Gouveia (2013) esclarece que, a tradição, realização, conformidade, segurança e poder, estimam pela estabilidade pessoal, submissão e manutenção da tradição. hierarquia dos nossos participantes juntamente com o hedonismo $(M=5,0 ; \mathrm{Dp}=0,81)$ que pode ser definido como a busca pelo prazer e de gratificação sexual. Assim fica claro que primeiro nossos participantes zelam pelos seus parentes e amigos, para depois considerar seu próprio prazer e buscar ser tolerante visando o bem-estar de todos e preservação dos recursos naturais, que também está inclusa no universalismo.

Tabela 3

Estatísticas de amostras emparelhadas

\begin{tabular}{|c|c|c|c|c|c|c|c|}
\hline & Média & $\mathbf{N}$ & $\begin{array}{l}\text { Desvio } \\
\text { Padrão }\end{array}$ & $\begin{array}{c}\text { Erro } \\
\text { padrão da } \\
\text { média } \\
\end{array}$ & $\mathbf{t}$ & df & $\begin{array}{c}\text { Sig. }(2 \\
\text { extremidades) }\end{array}$ \\
\hline Parte 1 & & & & \multirow[b]{2}{*}{12,354} & \multirow[b]{2}{*}{12,354} & \multirow[b]{2}{*}{132} & \multirow[b]{2}{*}{, 000} \\
\hline $\begin{array}{l}\text { Autotranscendência } \\
\text { Autopromoção }\end{array}$ & $\begin{array}{l}5,1489 \\
3,8045\end{array}$ & $\begin{array}{l}133 \\
133\end{array}$ & $\begin{array}{l}, 73181 \\
, 06081\end{array}$ & & & & \\
\hline Parte 2 & & & & \multirow[b]{2}{*}{7,897} & \multirow[b]{2}{*}{7,897} & \multirow[b]{2}{*}{127} & \multirow[b]{2}{*}{, 000} \\
\hline $\begin{array}{l}\text { AberturaMudança } \\
\text { Conservação }\end{array}$ & $\begin{array}{l}4,5957 \\
3,8045\end{array}$ & $\begin{array}{l}128 \\
133\end{array}$ & $\begin{array}{l}, 83838 \\
, 81206\end{array}$ & & & & \\
\hline
\end{tabular}


Portanto, os jovens participantes desta pesquisa tendem a valorizar e se preocupar com o outro, mas dando prioridade aos mais próximos aderindo, portanto, aos dois principais valores de autotranscedência que são o universalismo e a benevolência. Por outro lado, os jovens tendem a rejeitar os valores mais tradicionais como o poder, a segurança e o conformismo, se apegando a valores mais propícios à mudança, principalmente o hedonismo.

É importante ressaltar que Schwartz (1994) afirma que as condições contextuais em que se encontra os participantes influenciam para que alguns itens sejam mais escolhidos que outros. Portanto, o presente estudo trata de jovens estudantes universitário, integrados a uma instituição de ensino privada, que incentiva o crescimento individual, assim como competências e habilidades para a inserção no mercado de trabalho, que exige abertura às mudanças. Por outro lado, também se apresenta como uma instituição cristã que pauta seus valores em ensinamentos religiosos auto transcendentes.

A Tabela 4 demonstra correlação significativa entre abertura à mudança e autotranscedência $(\mathrm{r}=0,436 ; \mathrm{p}=0,00)$ e também com conservação $(r=0,313 \sim ; p=0,00)$. Significa que a autotranscedência aumenta e diminui na mesma direção que a conservação e a abertura a mudança. Esse resultado parece incongruente visto que a conservação e a abertura à mudança são polos opostos deste modelo. Reforçando isto, a autopromoção também se correlaciona positivamente com conservação ( $\mathrm{r}=0,353 \sim$; $\mathrm{p}=0,00)$, assim como com a abertura a mudança $(\mathrm{r}=0,221 \sim ; \mathrm{p}=0,00)$.

Tabela 4

Correlação

\begin{tabular}{|c|c|c|c|c|}
\hline & Autotranscendência & Autopromoção & Aber. Mudança & Conservação \\
\hline $\begin{array}{l}\text { Autotranscendência } \\
\text { (Correlação de Pearson) } \\
\text { Sig. (2 extremidades) } \\
\text { N }\end{array}$ & $\begin{array}{c}1 \\
134 \\
\end{array}$ & $\begin{array}{l}, 055 \\
, 527 \\
133 \\
\end{array}$ & $\begin{array}{c}, 436 * * \\
, 000 \\
132\end{array}$ & $\begin{array}{c}, 313 * * \\
, 000 \\
128\end{array}$ \\
\hline $\begin{array}{c}\text { Autopromocão } \\
\text { (Correlação de Pearson) } \\
\text { Sig. (2 extremidades) } \\
\mathrm{N}\end{array}$ & $\begin{array}{l}, 055 \\
, 527 \\
133 \\
\end{array}$ & $\begin{array}{c}1 \\
135 \\
\end{array}$ & $\begin{array}{l}, 221 * \\
, 010 \\
134 \\
\end{array}$ & $\begin{array}{c}, 353 * * \\
, 000 \\
129 \\
\end{array}$ \\
\hline $\begin{array}{c}\text { AberturaMudanca } \\
\text { (Correlação de Pearson) } \\
\text { Sig. (2 extremidades) } \\
\mathrm{N} \\
\end{array}$ & $\begin{array}{c}, 436 * * \\
, 000 \\
132 \\
\end{array}$ & $\begin{array}{c}, 221 * \\
, 010 \\
134 \\
\end{array}$ & $\begin{array}{c}1 \\
134 \\
\end{array}$ & $\begin{array}{l}, 212 \\
, 016 \\
128 \\
\end{array}$ \\
\hline $\begin{array}{c}\text { Conservação } \\
\text { (Correlação de Pearson) } \\
\text { Sig. (2 extremidades) } \\
\mathrm{N}\end{array}$ & $\begin{array}{c}, 313 * * \\
, 000 \\
128 \\
\end{array}$ & $\begin{array}{c}353 * * \\
, 000 \\
129 \\
\end{array}$ & $\begin{array}{l}, 212 * \\
, 016 \\
128 \\
\end{array}$ & 130 \\
\hline
\end{tabular}

Essas correlações positivas incongruentes com o modelo de Schwartz (1999) parecem ilustrar o que afirma La Taille (2009) sobre as contradições da cultura pósmoderna, na qual o sujeito, ao perceber-se em um momento histórico onde não há existência de referências seguras e perduráveis sente-se coagido a estar aberto para lidar com pequenas urgências que podem surgir. Muda-se o cenário político, surgem novas demandas econômicas, portanto se instala a incerteza de tempos que outrora eram certamente percebidos como sólidos. O autor enfatiza ainda que o homem contemporâneo por falta de referências de passado e sem perspectiva concretas de futuro não possui critério para hierarquizar valores, promovendo assim a horizontalidade desses valores e que em decorrência desse fenômeno, o homem pós-moderno enfrenta imprevisibilidade e instabilidade dos tempos líquidos (Bauman, 1998, citado por La Taille, 2009) que resultam na instabilidade dos valores que se equivalem e se revezam. 
Isso posto, cabe ressaltar que, os valores, estão presente em todas as ações cotidianas das pessoas, no entanto, a forma como os sujeitos as hierarquizam é que os diferenciam (Spadoni, 2016). Os resultados apresentados demonstram que os jovens universitários participantes desse estudo possuem uma clara hierarquia, na qual existem os valores preponderantes (Benevolência, Universalismo e Hedonismo) e os menos importantes (segurança, poder e conformidade). Demostram também que os valores de autotranscedência predominam sobre os de autopromoção e que os valores de abertura à mudança predominam sobre os valores de conservação. No entanto, quando analisamos as correlações entre esses polos organizadores dos valores no modelo de Schwartz (1999), percebemos incoerências que podem indicar certa instabilidade $\mathrm{e}$ incongruência na organização desta hierarquia, principalmente no que tange a oposição entre o conservadorismo e a abertura às mudanças.

Esse estudo também se interessou em investigar o que esses jovens pensam sobre o ensino de valores, a quem eles atribuem essa responsabilidade e quais os valores que eles pensam ter sido ensinados pelos seus professores.

\section{Valores ensinados pelos professores}

Para levantar os valores que os universitários consideram que foram ensinados pelos professores, optamos por utilizar uma técnica geralmente utilizada nos estudos sobre representações sociais. Essa técnica consiste em fazer uma pergunta de evocação pedindo que o participante escreva as três primeiras palavras ou expressões que vêm a sua mente. Essas respostas são tratadas cruzando a frequência pela ordem com que as palavras foram citadas.

Como se percebe na Tabela 5 a seguir, construída nos moldes propostos por Vèrges
(1994), no primeiro quadrante aparece a palavra respeito, caracterizada por uma baixa ordem de citação e por uma forte frequência, sendo, portanto, citada prioritariamente, diversas vezes pelos participantes. Isto significa que essa palavra, junto com as demais que se localizam no primeiro quadrante da tabela abaixo, são as mais importantes.

A palavra educação é a segunda mais proeminente da tabela, seguida por honestidade e ética, demonstrando que respeito, educação, honestidade e ética são, provavelmente os valores mais lembrados de prontidão pelos participantes. De acordo com o modelo de tipos motivacionais de Schwartz (1994) as palavras respeito, ética e educação são valores que visam à conformidade e estimam pela submissão e manutenção da tradição. Apenas o valor honestidade poderia condizer com o tipo motivacional benevolência, que diz respeito à busca e proteção do bem-estar das pessoas com quem se mantém relações de intimidade.

Isto indica que para esses universitários os principais valores ensinados pelos seus professores são de cunho conformista. Para Miller (citado por Ross e Schwartz, 1995) a conservação se caracteriza como uma ênfase na manutenção do status quo, sendo que para isto, ela possui a propriedade de limitar as ações de indivíduos ou grupos que possam ferir a ordem tradicional. Por isso são considerados valores sociocêntricos, que privilegia o coletivo sobre o individual.

Apenas o terceiro quadrante caracterizado por baixa ordem de citação e baixa frequência apresenta outros termos, considerados pouco importantes nessa pesquisa. 
Tabela 5

Evocações obtidas com base no termo indutor "Você se lembra de alguns valores morais que você aprendeu que foram ensinados pelos professores em algumas disciplinas? Cite-os.".

\begin{tabular}{ll}
\hline & Ordem de citação $<2,5 \quad$ Ordem de citação $>=2,5$ \\
\hline Frequência $>=7$ & Respeito $(50 ; 1,7)$ \\
& Educação $(19 ; 1,9)$ \\
& Honestidade $(18 ; 1,6)$ \\
& Ética $(13 ; 2,2)$ \\
& Não ensinou $(13 ; 1,3)$ \\
\hline & Compromisso $(6 ; 2,1)$ \\
& Dedicação $(5 ; 2)$ \\
& Responsabilidade $(4 ; 1,2)$ \\
Frequência $<7$ & Lembro $(4 ; 1)$ \\
& Moral $(4 ; 2,2)$ \\
& Para $(5 ; 2)$ \\
& Perseverança $(4 ; 2)$ \\
& Próximo $(4 ; 1,2)$ \\
& Ser $(4 ; 2,2)$ \\
\hline
\end{tabular}

\section{Responsabilidade do ensino de valores}

Foi solicitado que os participantes indicassem o quanto eles consideravam ser de responsabilidade da faculdade, do professor e/ou da família o ensino moral dos alunos, numa escala de 8 pontos a serem distribuídos, os participantes indicariam o tamanho da responsabilidade de cada item. Eles atribuíram aos familiares $57,14 \%$ da responsabilidade, aos professores apenas $28,57 \%$ e à faculdade $14,29 \%$.

Esses resultados demonstram uma crença de que a responsabilidade do ensino moral é predominantemente da família. Segundo La Taille (2009) é certo avaliarmos que a família tem fundamental importância na formação do ensino moral de crianças e adolescentes, pois é da praxe os filhos terem os pais como figuras influentes. Contudo, ela não é a única instituição responsável pela educação moral. Para ilustrar isto, o autor cita Kant e Durkheim (p.16) sendo que o primeiro afirmou que a família é apenas insuficiente e pouco adequada pois em vez de corrigir os defeitos da família, os reproduz. Já Emile Durkheim afirma:

Contrário à opinião demasiada difundida, segundo a qual a educação moral caberia antes de tudo à família, estimo que a função da escola no desenvolvimento moral pode e deve ser da mais alta importância (...) pois, se a família pode, sozinha, despertar e consolidar os sentimentos domésticos necessários à moral e mesmo, de forma mais geral, aqueles que estão na base das relações privadas mais simples, ela não é constituída de maneira a poder formar a criança para a vida em sociedade. (Durkheim, 1974, p. 16, citado por La Taille, 2009).

No entanto quando questionados sobre o quanto eles consideravam importante a relação entre professor e aluno no aprendizado desses valores morais, a média total foi de 3,7 (Dp=0,5; em uma escala onde 1 significava pouco importante e 4 significava muito importante), demonstrando que eles consideram bastante importante a relação com o professor para aquisição desses valores. $\mathrm{Ou}$ seja, a família é a principal responsável pelo ensino de valores, mas isso não exclui a importância dos professores.

Os acadêmicos ainda foram questionados o quanto eles acreditavam que seus professores eram preparados para ensinar esses valores morais citados acima, (em uma escala onde 1 significava pouco preparado e 4 significava muito preparado), a média total das respostas dos acadêmicos foi de 3,3 $(\mathrm{DP}=0,7)$, demonstrando que na percepção desses 
universitários, os professores estão preparados para ensinar valores morais durante o processo de educação.

Além disso, foi demandado o quanto eles consideravam importante o conteúdo ministrado nas disciplinas no aprendizado desses mesmos valores, e a média total dessa questão foi de 3,6 ( $\mathrm{Dp}=0,5$; em uma escala onde 1 significava pouco importante e 4 significava muito importante) representando, portanto, que o conteúdo ministrado em aula era conjuntamente importante para aquisição de tais valores.

Em resumo, os universitários atribuem aos professores um papel secundário no ensino de valores quando comparado á importância da família. Mas eles também consideram que estes são bem preparados para fazê-lo, que ensinam através da relação com os alunos e do conteúdo das disciplinas.

Neste sentido, para La Taille (2009), a instituição educacional representa para seus alunos uma prática de passagem da família, caracterizada como um espaço privado, para a vida em sociedade caracterizada como um espaço público, por isso nela são trabalhadas as dimensões morais necessárias para participar da vida em sociedade.

\section{Considerações finais}

Através desta pesquisa de campo com universitários, podemos concluir que esses jovens pesquisados possuem uma clara hierarquia de valores que privilegia o bem do outro antes de procurar seus interesses, portanto de carácter auto transcendente. No entanto, esse outro é primeiramente as pessoas próximas e amadas (família e amigos), para depois considerar o outro universal, geral e potencialmente desconhecido.

Em relação a si mesmo, os jovens optam pelo hedonismo, ao invés da autopromoção indicando uma busca pelo prazer imediato ao invés de um planejamento visando sua realização pessoal à longo prazo. Nesse sentido, os jovens se localizam no modelo de
Schwartz (1994) nas dimensões da autotranscedência e da abertura à mudança indicando que se importam com os outros e estão abertos às mudanças.

Esse dado é reafirmado pelos valores que eles indicaram como menos importantes, por serem todos eles conservadores. No entanto, eles atribuem aos professores o papel de ensinar esses valores conservadores, que eles consideram pouco importantes, e ainda afirmam que os professores estão preparados para ensiná-los e que o fazem com competência através da relação entre professor-aluno e dos conteúdos das disciplinas.

Abaixo desta hierarquia dos principais valores (benevolência, hedonismo e universalismo), a hierarquia de valores se torna confusa sugerindo um achatamento que iguala os demais valores.

Os resultados demonstraram que há um conflito dentre os valores hierarquizados como mais importantes pelos universitários.

Vale ainda ressaltar o conflito no caráter dos três principais valores escolhidos por nossos participantes. Por um lado, estão a benevolência e o universalismo, que são valores autotranscedentes, e por outro lado, o hedonismo, que é um valor intrínseco, voltado para à abertura à mudança. Parece possível concluir que estes são os valores que os universitários consideram ter sido ensinados pela família. Visto que aos professores, os estudantes atribuem o ensino de valores conservadores, é possível que haja um choque entre os valores que são ensinados pela família e os que são ensinados pelos professores.

Essas conclusões, demonstram provavelmente um cenário de mudanças sociais, políticas e econômicas que são responsáveis por gerarem transformações na maneira que o homem interage no mundo. Muitos autores consideraram que o século XX foi marcado por mudanças significativas na maneira de ser homem e de viver no mundo. La Taille (2009) ilustra como "máquina hedonista", a maneira que o homem 
contemporâneo se comporta, buscando preencher a falta de sentido com incessantes momentos de prazeres, bem-estar, conforto e socializações sem conflitos. Para Simmel (2005) o excesso de estímulo da vida pósmoderna desperta nos sujeitos a necessidade de voltar-se para dentro, voltar-se para os seus, onde se sinta seguro e sobre controle do mundo.

Outro ponto a ser salientado, diz respeito a atribuição dos universitários sobre a responsabilidade do ensino de valores ser exercido preponderantemente pela família. Em função disso, por ser a família que mais ensina tais valores, a benevolência venha ser o valor mais importante nesta hierarquia. Visto que este valor diz justamente a respeito da preservação da família, a colocação desta em primeiro lugar, em detrimento de todo o restante dos indivíduos. E isso pode significar que, se houver alguma situação em que a família seja colocada em pauta juntamente com o restante da sociedade, os jovens participantes irão optar pela a família. O familismo como afirma Almeida (2015) é uma característica do povo brasileiro que pensamos poder ser um meio termo entre o individualismo crescente e o coletivismo do passado, mas que denota um certo egoísmo, pois privilegia primeiro os familiares e amigos para depois considerar o bem estar dos outros.

Os valores tradicionais são os menos importantes para os estudantes, mas são justamente esses que são atribuídos aos professores, indicando uma possível desvalorização dos professores que podem estar sendo considerados como anacrônicos. Esse cenário demonstra um descompasso entre os valores dos alunos e dos professores, pois enquanto uns valorizam valores a benevolência, o hedonismo e universalismo, os outros tentam ensinar valores conservadores, o que certamente pode provocar conflitos na convivência.

Abarcando a teoria de La Taille (2009) os valores são investimentos afetivos, e por isso eles podem e devem ser instrumentos de reflexão, porém, nem sempre se tem consciência que são esses valores que mobilizam as ações individuais. Por isso, espera-se que este estudo desperte a reflexão a respeito dos valores que permeiam o cotidiano de jovens universitários e professores, e, como essa organização atual dos valores podem influenciar nos comportamentos cotidianos dos universitários e nas práticas de ensinoaprendizagem dos professores.

\section{Referências}

Almeida, C. A. (2015). A cabeça do brasileiro. Rio de Janeiro: Record. Cunningham, L. S., \& Reich, J. J. (2002). Culture and Values: A Survey of the Western Humanities. Stamford: Cengage Learning.

Flament, C., \& Rouquette, M.-L. (2003). Anatomie des idées ordinaires. Commentétudier les représentations sociales. Paris: Armand Colin.

Gouveia, V. V. (2013). Teoria funcionalista dos valores humanos: fundamentos, aplicações e perspectivas. São Paulo: Casa do Psicólogo.

Lima, T. J. S. (2012). Modelos de valores de Schwartz e Gouveia: Comparando conteúdo, estrutura e poder preditivo (Dissertação de Mestrado). Universidade
Federal da Paraíba, João Pessoa, Brasil.

Recuperado de https://repositorio.ufpb.br/jspui/handle/tede 16903

Menezes, I., Costa, M. E., \& Campos, B. P. (1989). Valores de estudantes universitários. Cadernos de consulta psicológica, 5, 53-68. Recuperado de https://sigarra.up.pt/fpceup/pt/pub_geral.pu b_view?pi_pub_base id $=81714$

Porto, J. B., Tamayo, A. (2007). Estrutura dos valores pessoais: a relação entre valores gerais e laborais. Psicologia: Teoria e Pesquisa, 23(1), 63-70. doi: 10.1590/S0102-37722007000100008

La Taille, Y. (2009), Formação ética: do tédio ao respeito de si. São Paulo: Artmed. 
Rokeach, M. (1973). The nature of human values. New York: Free press.

Rokeach, M. (1979). The two-value model of political ideology and British politics.

British Psychological Society, 18(2), 169-

172. doi: $10.1111 / \mathrm{j} .2044-$

8260.1979.tb00321.x

Ros, M., Schwartz, S. H. (1995). Jerarquia de valores en paises de la Europa occidental: una comparacion transcultural. Reis, (69), 69-88. doi: $\underline{10.2307 / 40183777}$

Schwartz, S. H. (1992). Universals in the context and structure of values: theoretical advances and empirical tests in 20 countries. In M. Zanna (Org.), Advances in experimental social psychology (vol. 25, pp. 1-65). Orlando: Academic Press. doi: 10.1016/S0065-2601(08)60281-6

Schwartz, S. H. (1994). Are there universal aspects in the structure and contents of human values? Journal of Social Issues, 50,
19-45. doi: $10.1111 / \mathrm{j} .1540-$ 4560.1994.tb01196.x

Schwartz, S. H. (2003). A proposal for measuring value orientations across nations. Questionnaire package of the european social survey, 259(290), 261.

Simmel, G. (2005). As grandes cidades e a vida do espírito (1903). Mana, 11(2), 577591. doi: $10.1590 / \mathrm{S} 0104-$ 93132005000200010

Spadoni, L. (2016). Psicologia realmente aplicada ao direito. São Paulo: LTr8.

Verges, P. (1994). Approche du noyau central: propriétés quantitatives et structurales. In C. Guimelli, (Org.), Structures et transformations des représentations sociales (pp. 233-253). Lausanne: Délachaux et Niestlé. Recuperado de https://www.scielo.br/pdf/prc/v16n3/v16n3 a03.pdf 


\section{Dados sobre os autores:}

- Mickaele Pabline Siqueira Dutra: Psicóloga pesquisadora e clínica, atuando pelo Instituto de Análise do comportamento (Anápolis).

- Luanna Gomes Silva Pereira: Psicóloga graduada pelo Centro Universitário de Anápolis UniEVANGÉLICA (2020), desde 2017 envolvida com pesquisas acerca dos valores morais, finalidades educativas e representações que permeiam o cotidiano de alunos e professores em Goiás.

- Lila Maria Spadoni Lemes: Doutora em Psicologia pela Université Paris Descartes, Sorbonne, revalidado pela UNB. Professora assistente da Pontifícia Universidade Católica de Goiás, atua na graduação, no Programa de Pos-graduação em Psicologia (PSSP- PUC-GO) e no Programa de Pós-educação em Educação (PPGE).

- Margareth Regina Gomes Veríssimo de Faria: Doutora em Psicologia pela Pontifícia Universidade Católica de Goiás. Pós doutora em psicologia pela USP de Ribeirão Preto, Atua como docente da Graduação e Pós-Graduação Stricto Sensu em Psicologia na PUC Goiás como professora colaboradora. No Centro Universitário de Anápolis atua como docente da Graduação e Pós-Graduação Lato Sensu. Participa como membro do Comitê Institucional de Pesquisa e Inovação (CIPI) e como membro do Comitê de Ética do Centro Universitário de Anápolis.

Declaração de Direito Autoral

A submissão de originais para este periódico implica na transferência, pelos autores, dos direitos de publicação impressa e digital. Os direitos autorais para os artigos publicados são do autor, com direitos do periódico sobre a primeira publicação. Os autores somente poderão utilizar os mesmos resultados em outras publicações indicando claramente este periódico como o meio da publicação original. Em virtude de sermos um periódico de acesso aberto, permite-se o uso gratuito dos artigos em aplicações educacionais e científicas desde que citada a fonte conforme a licença CC-BY da Creative Commons. 